\title{
Rat lung transplantation model: modifications of the cuff technique
}

\author{
Dong Tian ${ }^{1,2,3 \#}$, Haruhiko Shiiya ${ }^{1,4 \#}$, Masaaki Sato $^{1}$, Jun Nakajima ${ }^{1}$ \\ ${ }^{1}$ Department of Thoracic Surgery, The University of Tokyo Graduate School of Medicine, Tokyo, Japan; ${ }^{2}$ Department of Thoracic Surgery, Affiliated \\ Hospital of North Sichuan Medical College, Nanchong, China; ${ }^{3}$ Department of Thoracic Surgery, West China Hospital, Sichuan University, \\ Chengdu 610041, China; ${ }^{4}$ Department of Cardiovascular and Thoracic Surgery, Hokkaido University Graduate School of Medicine, Sapporo, Japan \\ Contributions: (I) Conception and design: D Tian, H Shiiya, M Sato; (II) Administrative support: None; (III) Provision of study materials or patients: \\ D Tian, H Shiiya; (IV) Collection and assembly of data: D Tian, H Shiiya; (V) Data analysis and interpretation: D Tian, H Shiiya; (VI) Manuscript \\ writing: All authors; (VII) Final approval of manuscript: All authors. \\ \#These authors contributed equally to this work. \\ Correspondence to: Masaaki Sato, MD, PhD. Department of Thoracic Surgery, The University of Tokyo Graduate School of Medicine, 7-3-1 Hongo, \\ Bunkyo-ku, Tokyo 113-8655, Japan. Email: satom-sur@h.u-tokyo.ac.jp.
}

Background: Although the cuff technique in rat lung transplantation (LTx) has a long history, it remains technically challenging. We have developed key tricks and modifications in the devices and the cuff technique that optimize the rat LTx model to achieve successful operations during a short learning period.

Methods: Altogether, 180 consecutive rats underwent orthotopic left LTx performed by a single surgeon using our modified devices and procedures. Allogeneic and syngeneic transplantation were performed using Lewis rats as recipients and Brown Norway and Lewis rats as donors. Allogeneic recipients were treated with cyclosporine during the first week. Recipients were sacrificed at various time points after $\geq 2$ weeks.

Results: A special cuff-preparation plate was created using a petri dish and two foam blocks. This modified plate stabilizes the preparation and prevents donor lung compression. A " $\perp$ "-shaped incision was carved into the front wall of the pulmonary artery (PA) using micro-scissors. "V"-shaped incisions were made from the inferior-to-superior branches of the pulmonary vein (PV) and bronchus. A "pendulum model" was applied at implantation to make the hilar anastomosis tension-free and technically easier to perform. There were no intraoperative complications. Ten rats (5.6\%) experienced partial or full pulmonary atelectasis. Five deaths $(2.8 \%)$ due to pleural effusion occurred during the follow-up period. The operative times for heartlung block retrieval, cuff preparation, cold ischemia, warm ischemia, and total procedure time were $8.4 \pm 0.8$, $11.6 \pm 1.5,25.1 \pm 2.2,8.1 \pm 1.2$, and $46.7 \pm 2.8 \mathrm{~min}$, respectively.

Conclusions: The key tricks and improvements we made in the cuff technique for rat LTx provided the advantages of expeditiousness, a low complication rate, and a high success rate.

Keywords: Cuff technique; key trick; lung transplantation (LTx); modification; rat

Submitted Dec 25, 2019. Accepted for publication Feb 06, 2020.

doi: $10.21037 /$ atm.2020.02.46

View this article at: http://dx.doi.org/10.21037/atm.2020.02.46

\section{Introduction}

The cuff technique of the rat lung transplantation (LTx) model was first reported by Mizuta et al. in 1989 (1). Various modifications and improvements have been reported in recent years (2-5). Although it has been thought that any trained surgeon could perform this technique successfully, the difficulties and disadvantages of this model still exist and often require a long learning curve (6). In addition, complications such as twisted blood vessels, pulmonary atelectasis, bleeding, and thoracic effusion still occur, although some recipient rats survive without any symptoms (4). Because improper devices and procedures for this technique could potentially lead to frustration and failure to complete one's training, disclosing the improvements of the devices and procedures may shorten and simplify complex steps, thereby encouraging the trainee to continue. This article 


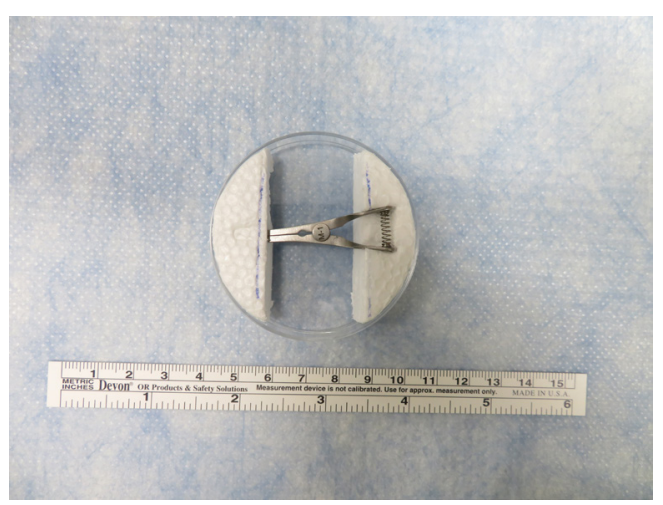

Figure 1 Graft preparation plate is modified by two foam blocks attached to a petri dish. A groove and hole were carved on the foam blocks to match the ends of a bulldog clamp.

describes the key tricks and modifications of devices used in this improved cuff technique that optimize the rat LTx model, helping to achieve successful operations in a shorter time with a lower complication rate.

\section{Methods}

\section{Devices and instruments}

Small, handheld surgical instruments and larger equipment for rat LTx were used as in previous studies of Kyoto University $(7,8)$ and as described in Figures $S 1-S 3$. We have modified the device for cuff preparation. We used a petri dish attached to two foam blocks. A groove and hole were carved on the foam blocks to match the ends of a bulldog clamp (Natsume Seisakusho Co., Ltd, Tokyo, Japan) (Figure 1). To prevent lung tissue injury, we modified the ends of the cuff tail from rectangular to round (Figure S4).

\section{Animals}

Male Brown Norway and Lewis rats were purchased from Japan SLC, Inc. (Hamamatsu, Japan). Models of syngeneic and allogeneic transplantation were performed as described previously (7) (further details are described in supplementary material). Animals were sacrificed at $\geq 2$ weeks postoperatively. All rats were maintained under specific pathogen-free conditions at The University of Tokyo. Animals were fed a standard diet and provided with water ad libitum.

This study was approved by the Experimental Animal Ethics Committee of The University of Tokyo (No.
H19-027). All procedures were performed in accordance with the guidelines of the Institutional Animal Care and Use Committee at The University of Tokyo.

\section{Time-interval definitions}

The donor operation time was the interval from incision of the donor rat to excision of the heartlung block. The cuff preparation time was the interval from excision of the heart-lung block to completion of cuff placement. The cold ischemia time was defined at the time from flushing the donor lungs in situ with ET-Kyoto solution (Otsuka, Tokushima, Japan) to graft removal from hypothermic storage. The warm ischemia time was set as the interval from donor lung removal from the ice until restoration of the reperfusion. The total procedure time was the interval from the donor's skin incision until closure of the recipient's incision.

\section{Donor procedures}

Donor heart-lung block retrieval was performed as in previous studies $(7,8)$. After the hilar structures of the left main bronchus, pulmonary artery (PA), and pulmonary vein (PV) with part of the left atrium were dissected, the hilar structures were consecutively everted around the cuff and secured by a preparatory 6-0 slipknot. Thereafter, the graft was rewrapped by organ perfusate-soaked paper and stored on ice for implantation (Videos 1,2).

\section{Recipient procedure}

A thoracotomy incision was made from the area of a palpable cardiac impulse on the chest wall and extended dorsally for about 3-4 cm. A blepharostat was used as a chest retractor (Speculum BANGERTER Large Right; Inami, Tokyo, Japan) to expose the thoracic cavity. The hilar structures were dissected and then clamped distally and proximally using two Satinsky clamps. The Satinsky clamps were then fixed in plastic clay to place mild tension on the bronchovascular structures. $\mathrm{A} \perp_{\text {-shaped incision was made }}$ on the front wall of the PA using micro-scissors. V-shaped incisions were made from the inferior-to-superior branches of the PV and bronchus (Figure 2).

The "pendulum model" method was used for implantation. The bronchus was implanted first. The native bronchus and cuff body were secured using a preparatory 6-0 nylon knot positioned loosely around the recipient bronchus. The 


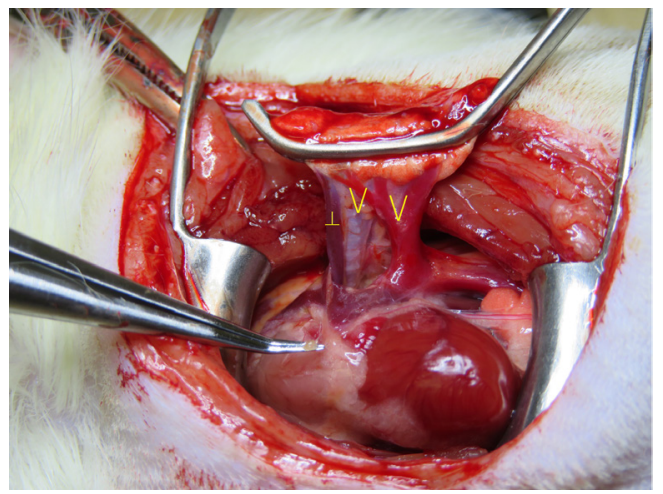

Figure 2 Hilar bronchovascular structure incisions are " $\mathrm{V}$ "-shaped on both bifurcations of the pulmonary vein and bronchus and " $\perp$ "-shaped for the pulmonary artery.

superior bifurcation of the bronchus was excised to eliminate any overlaps between the bronchus and the PA. The donor lung was then repositioned to allow a PA anastomosis without tension. The donor lung was repositioned again to allow creation of the PV anastomosis without tension. The PA and PV were implanted in analogous fashion as with the bronchus. After excising the left native lung parenchyma, the end rim of the native structures was cut for debonding before reperfusion (Figure S5) (Video 3).

\section{Assessment of chest-radiography and bistology}

Post-transplantation rats underwent chest plain radiography on postoperative day 7 to screen for complications such as atelectasis or to have recorded complications at the time of sacrifice. For routine histological evaluation, lung grafts were fixed in $10 \%$ formalin, embedded in paraffin, sectioned into $4-\mu \mathrm{m}$ thickness, and stained with hematoxylin-eosin.

\section{Statistical analysis}

Results were expressed as means \pm SD. The results were analyzed by SPSS 24.0 software (IBM, Armonk, NY, USA).

\section{Results}

\section{Key tricks and modifications on techniques and devices}

The following devices and techniques were improved and modified in our series (Table 1).

* Regarding the devices, we modified the cuff preparation plate, which now contains a petri dish attached to two foam blocks. A groove and hole were carved on the foam blocks to match the ends of a bulldog clamp. This modified plate stabilized the operation, was less injurious, and made the procedure easier to master.

* When locating the incision site on the recipient, the region of apical impulse, or palpable cardiac impulse on the chest wall, was first confirmed and then extended dorsally for about $3-4 \mathrm{~cm}$. This position was located more easily and was suitable for the following implantation. Before implantation, a

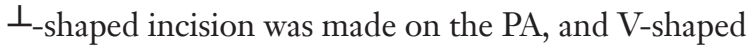
incisions were made on the PV and bronchus. These improvements made implantation easier and lacerations on the structures less likely to occur.

* The "pendulum model" method was used for implantation. First, the bronchus was implanted. Thereafter, the donor lung was repositioned to close the PA and PV, thereby allowing a tensionfree anastomosis. In addition, we modified the cuff so it had a round tail, used the slip-knots for cuff preparation, and debonded the end rim of the native structures after implantation.

\section{Outcomes of rat LTX}

In a consecutive series, 180 (syngeneic 33, allogeneic 147) anastomoses were completed by one performer (D Tian) without lacerations, twisting, or angulation of intraoperative bronchovascular structures and without bleeding at the vascular anastomosis. There were no intraoperation deaths, pneumothorax, or vessel thromboses. Partial or full pulmonary atelectasis was observed in 10 cases (5.6\%). Five deaths $(2.8 \%)$ were found at a follow-up time of 3-7 days, most likely due to pleural effusion.

\section{Operation time of rat LTx of all procedures}

The mean weights of the rats at the time of transplant of Lewis and Brown Norway rats were 239.7 \pm 42.8 and $291.2 \pm 23.0 \mathrm{~g}$, respectively. The mean operative times of heart-lung block retrieval, cuff preparation, cold ischemia, warm ischemia and total procedure time are seen in Table 2.

\section{Discussion}

Although several studies have introduced technical 
Table 1 Key tricks and modifications on techniques and devices

\begin{tabular}{|c|c|c|c|}
\hline $\begin{array}{l}\text { Procedures and } \\
\text { devices }\end{array}$ & Previous status & Modifications & Advantages \\
\hline Cuff & Rectangular tail & Round tail (Figure S4) & Round tail can prevent accidental injury \\
\hline $\begin{array}{l}\text { Recipient } \\
\text { thoracotomy }\end{array}$ & $\begin{array}{l}\text { 3rd/4th Intercostal } \\
\text { space; inferior margin } \\
\text { of the scapula }\end{array}$ & $\begin{array}{l}\text { Region of apical impulse (Video } 3 \text {, } \\
\text { 3"-4") }\end{array}$ & $\begin{array}{l}\text { This anatomical landmark can easily confirm the } \\
\text { correct skin site for incision }\end{array}$ \\
\hline $\begin{array}{l}\text { Hilum structure } \\
\text { incisions }\end{array}$ & $\begin{array}{l}\text { Transverse or } \\
\text {--shaped incision on } \\
\text { the front wall }\end{array}$ & $\begin{array}{l}\text { (I) } \perp_{\text {-shaped incision for PA; (II) }} \\
\text { V-shaped incisions on the bifurcations } \\
\text { of the PV and bronchus (Video } 1 \text { ) }\end{array}$ & $\begin{array}{l}\text { (I) } \perp \text {-Shaped incision can prevent laceration of } \\
\text { pulmonary artery; (II) V-shaped incisions form a wide } \\
\text { rim of structure ostium that can be easily implanted } \\
\text { and free of laceration }\end{array}$ \\
\hline Implantation & $\begin{array}{l}\text { Single direction with } \\
\text { PV or PA first }\end{array}$ & $\begin{array}{l}\text { "Pendulum model" for implantation } \\
\text { (Video 3: 3'40"-7'03") }\end{array}$ & "Pendulum model" method is easy for implantation \\
\hline
\end{tabular}

PA, pulmonary artery; PV, pulmonary vein.

Table 2 Overall operative time for rat lung transplantation, including all procedures

\begin{tabular}{lc}
\hline Single procedure $^{*}$ & Operative time $(\mathrm{min})$ \\
\hline Heart-lung block retrieval & $8.4 \pm 0.8$ \\
Cuff preparation & $8.1 \pm 1.4$ \\
Cold ischemia & $26.4 \pm 2.2$ \\
Warm ischemia & $8.1 \pm 1.2$ \\
Total procedure & $48.0 \pm 2.8$ \\
\hline
\end{tabular}

*, The procedures are defined as follows: heart-lung block retrieval: from incision on donor rat to excision of heart-lung block; cuff preparation: from excision of left donor lung to completion of cuff placement; cold ischemia: from flushing the donor lungs in situ with ET-Kyoto solution to graft removal from hypothermia storage; warm ischemia: from donor lung removal from ice until restoration of reperfusion; total procedure: from donor skin incision until closure of the recipient incision.

modifications for rodent LTx after Mizuta and colleagues first reported the cuff technique (1), some important and difficult key procedures have not been described. Rat LTx remains a difficult procedure, necessitating a long learning curve. In this study, we modified the operative devices and the cuff techniques to make it easier to master the procedure with a low complication rate and a high success rate. Using this modified technique, one author (H Shiiya) completed the first successful case at the 10th trying. Because it is a more expeditious operation, the ischemic times were shorter than those in a previous study (1) with fewer complication and no intraoperative deaths.
Only a few studies have reported on the instruments used for cuff preparation, although instruments can determine the success of this technique in the rat LTx model. Sugimoto et al. (9) used a petri dish for cuff preparation. With their technique, the donor lung was compressed and unstable when the cuff was created. A previous study reported the cuff preparation time at $18.7 \mathrm{~min}$, which more than twice that of our technique (5). We introduced a modified cuff preparation plate that could stabilize the cuff preparation, making it easier to master and more expeditious. With this improved device, the cuff preparation time was only $8.1 \mathrm{~min}$, with no structural lacerations in our series.

The skin incision of the recipient is important for transplantation. It is impossible to measure the intercostal space on a rat before surgery. Most previous reports that described the incision location, however, relied on different intercostal spaces $(3-6,10,11)$. Habertheuer et al. (12) started the skin incision $1 \mathrm{~cm}$ below the inferior margin of the scapula, which is unreliable because of the scapula is easily mobilized. In our series, we located the region of palpable cardiac impulse on the chest wall. This apical impulse region is at the level of the third or fourth intercostal space, as previously described $(4,6,13,14)$. It seems more useful, however, to follow this apical impulse when performing rat LTx. Our series showed no failures in placing a suitable incision.

Another key trick is to locate the incisions on the recipient's PV, bronchus, and PA. To shorten the warm ischemia period and minimize pulmonary injury, an expeditious technique is important. Most of the previous 
reports made a transverse incision on the front wall of the recipient's hilar structures $(3,9,12,15,16)$. Guo et al. (5) made the incision in a -shape toward all the structures. Jungraithmayr et al. (16) made the incision on the lower branch of the PV. We first introduced the V-shaped incisions from the inferior-to-superior branches on the PV and bronchus cuffs. This $\mathrm{V}$-shaped incision follows a wide rim of structure ostium, which allows the donor graft to be easily implanted without laceration. To match the lengths of

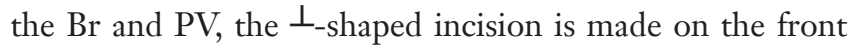
wall of the PA, which can well prevent proximal laceration at implantation. Guo et al. (5) reported a 5\% intraoperative failure rate of their technique due to bleeding and PV injury during the operation. Our study showed no intraoperative failures with hilar structure lacerations.

The "pendulum model" method for implantation was proposed in our study. Previous investigators often chose vessels as the first step. Rajab et al. (11) addressed PV first, followed sequentially with the bronchus and PA. Sugimoto et al. (9) went in the opposite direction, with the PA, bronchus, and PV, respectively. In our study, we anastomosed the bronchus first because, compared with vessels, it is structurally solid and easy to anastomose without laceration. In addition, we cut the superior bifurcation of the bronchus before the PA anastomosis because the bronchus and PA are always located adjacent to each other. Previous studies have not been concerned about the rim of the native hilum structures before reperfusion. Because the rim of the structures may contract and compress the graft structures, we cut the rim of the native structures to release them. With this technique, no vessel thrombosis, inadequate blood supply, or airway compression occurred after reperfusion and reinflation. Regarding the implantation time, previous studies reported an implantation time (warm ischemia time) of 15.2-20.0 $\mathrm{min}(5,6,12)$. With our modified implantation technique, the warm ischemia time was only $8.1 \mathrm{~min}$.

Previous studies also showed follow-up survival rates of $<90 \%$. The intraoperative deaths were mainly due to pleural effusion, venous cuff failure, or pyothorax $(1,5,12)$. Habertheuer et al. (12) reported about $18.9 \%$ cases were lost because of severe pleural effusions during the postoperative period. With our approach, the total follow-up survival rate was $97.2 \%$ (175/180), with no intraoperative deaths. A high success rate not only saves cost and time, it can strengthen the operator's confidence during surgery. All five deaths in our study were most likely due to pleural effusion. Minor bleeding from intercostal muscles is difficult to detect and may have caused the pleural effusion. As effusion accumulates, it may compress the grafted lung, causing a life-threatening complication. Thus, careful inspection is necessary before chest closure.

Pulmonary atelectasis is a common, severe complication of rat LTx. Although a rat can survive without obvious symptoms, the animal may not be used for further evaluation. In our study, only $5.6 \%$ of rats experienced graft atelectasis during the follow-up period, which appears to be an acceptable result for the rat LTx model. In our series, the post-LTx complications and follow-up deaths were rare. Reperfusion injury, a major cause of graft injury, is related to the ischemia time. A decrease in reperfusion pressure is thought to minimize this complication (17-19).

\section{Conclusions}

We developed modifications of devices and procedures of the cuff technique for the rat LTx model. The advantages of this modified cuff technique include its expeditiousness, low complication rate, and high rate of success. Our improvements could further facilitate rat LTx in a feasible, reproducible manner.

\section{Acknowledgments}

The authors acknowledge the Japan-China Sasakawa Medical Association for its contribution to this work. We thank the members of the Department of Thoracic Surgery, Graduate School of Medicine, Kyoto University, especially Dr. Akihiro Takahagi, Professor Toyofumi Chen-Yoshikawa and Professor Hiroshi Date for training one author (D Tian) in the original technique of rat LTx in 2017. We thank Nancy Schatken, BS, MT (ASCP), from Edanz Group (https://en-author-services.edanzgroup.com/), for editing a draft of this manuscript.

Funding: This study was funded by grant JSPS KAKENHI $17 \mathrm{H} 01581$ (to M Sato).

\section{Footnote}

Provenance and Peer Review: This article was commissioned by the Guest Editors (Masaaki Sato and Dong Tian) for the series "Strategies to Achieve Long-Term Success of Lung Transplantation" published in Annals of Translational Medicine. The article was sent for external peer review organized by the Guest Editors and the editorial office. 
Conflicts of Interest: The series "Strategies to Achieve LongTerm Success of Lung Transplantation" was commissioned by the editorial office without any funding or sponsorship. MS and DT served as the unpaid Guest Editors of the series. DT serves as an unpaid Section Editor of Annals of Translational Medicine from Oct 2019 to Sep 2020. The other authors have no other conflicts of interest to declare.

Ethical Statement: The authors are accountable for all aspects of the work in ensuring that questions related to the accuracy or integrity of any part of the work are appropriately investigated and resolved. The institutional Animal Care and Use Committee of The University of Tokyo (Tokyo, Japan) authorized this study (approval No. H19-027).

Open Access Statement: This is an Open Access article distributed in accordance with the Creative Commons Attribution-NonCommercial-NoDerivs 4.0 International License (CC BY-NC-ND 4.0), which permits the noncommercial replication and distribution of the article with the strict proviso that no changes or edits are made and the original work is properly cited (including links to both the formal publication through the relevant DOI and the license). See: https://creativecommons.org/licenses/by-nc-nd/4.0/.

\section{References}

1. Mizuta T, Kawaguchi A, Nakahara K, et al. Simplified Rat Lung Transplantation Using a Cuff Technique. J Thorac Cardiovasc Surg 1989;97:578-81.

2. Okazaki M, Krupnick AS, Kornfeld CG, et al. A mouse model of orthotopic vascularized aerated lung transplantation. Am J Transplant 2007;7:1672-9.

3. Zhai W, Ge J, Inci I, et al. Simplified rat lung transplantation by using a modified cuff technique. J Invest Surg 2008;21:33-7.

4. Goto T, Kohno M, Anraku M, et al. Simplified Rat Lung Transplantation Using a New Cuff Technique. Ann Thorac Surg 2012;93:2078-80.

5. Guo H, Nie J, Fan K, et al. Improvements of surgical techniques in a rat model of an orthotopic single lung transplant. Eur J Med Res 2013;18:1.

6. Kubisa B, Schmid RA, Grodzki T. Model of single left rat lung transplantation. Relation between surgical experience and outcomes. Rocz Akad Med Bialymst 2003;48:70-3.

7. Miyamoto E, Motoyama H, Sato M, et al. Association of Local Intrapulmonary Production of Antibodies Specific to Donor Major Histocompatibility Complex Class I With the Progression of Chronic Rejection of Lung Allografts. Transplantation 2017;101:e156-65.

8. Takahagi A, Shindo T, Chen-Yoshikawa TF, et al. Trametinib Attenuates Delayed Rejection and Preserves Thymic Function in Rat Lung Transplantation. Am J Respir Cell Mol Biol 2019;61:355-66.

9. Sugimoto R, Nakao A, Nagahiro I, et al. Experimental orthotopic lung transplantation model in rats with cold storage. Surg Today 2009;39:641-5.

10. Li W, Sugimoto S, Lai JM, et al. Orthotopic vascularized right lung transplantation in the mouse. J Thorac Cardiovasc Surg 2010;139:1637-43.

11. Rajab TK. Anastomotic techniques for rat lung transplantation. World J Transplant 2018;8:38-43.

12. Habertheuer A, Kocher A, Laufer G, et al. Innovative, simplified orthotopic lung transplantation in rats. J Surg Res 2013;185:419-25.

13. Marck KW, Wildevuur CR. Lung transplantation in the rat: I. Technique and survival. Ann Thorac Surg 1982;34:74-80.

14. Jungraithmayr W, Weder W. The Technique of Orthotopic Mouse Lung Transplantation as a Movie - Improved Learning by Visualization. Am J Transplant 2012;12:1624-6.

15. Suzuki H, Fan L, Wilkes DS. Development of Obliterative Bronchiolitis in a Murine Model of Orthotopic Lung Transplantation. J Vis Exp 2012. doi: 10.3791/3947.

16. Jungraithmayr WM, Korom S, Hillinger S, et al. A mouse model of orthotopic, single-lung transplantation. J Thorac Cardiovasc Surg 2009;137:486-91.

17. Bhabra MS, Hopkinson DN, Shaw TE, et al. Critical importance of the first 10 minutes of lung graft reperfusion after hypothermic storage. Ann Thorac Surg 1996;61:1631-5.

18. Bhabra MS, Hopkinson DN, Shaw TE, et al. Controlled reperfusion protects lung grafts during a transient early increase in permeability. Ann Thorac Surg 1998;65:187-92.

19. Pierre AF, DeCampos KN, Liu MY, et al. Rapid reperfusion causes stress failure in ischemic rat lungs. J Thorac Cardiovasc Surg 1998;116:932-42.

Cite this article as: Tian D, Shiiya H, Sato M, Nakajima J. Rat lung transplantation model: modifications of the cuff technique. Ann Transl Med 2020;8(6):407. doi: 10.21037/atm.2020.02.46 
For allogeneic transplant, 9- to 10-week-old Brown Norway weighing about $250 \mathrm{~g}$ are used as donors and 11- to 12-old Lewis weighing $300 \mathrm{~g}$ are used as recipients.

For syngeneic transplant, Lewis rats are used as both donors and recipients. Allogeneic LTx recipients were subcutaneously administered $25 \mathrm{mg} / \mathrm{kg}$ CsA (Novartis pharma, Tokyo, Japan) on 4 days in the first week.

All recipients were executed $0.5 \mathrm{~g} / \mathrm{kg}$ cefazolin sodium (Nichi-Iko Pharmaceutical Co, Toyama, Japan), $30 \mathrm{mg} / \mathrm{kg}$ Methylprednisolone Sodium Succinate (Pfizer, Tokyo, Japan) and $10 \mathrm{mg} / \mathrm{kg}$ Furosemide (Teva Takeda Pharma Ltd, Aichi, Japan) at postoperative day 1 and day 2.

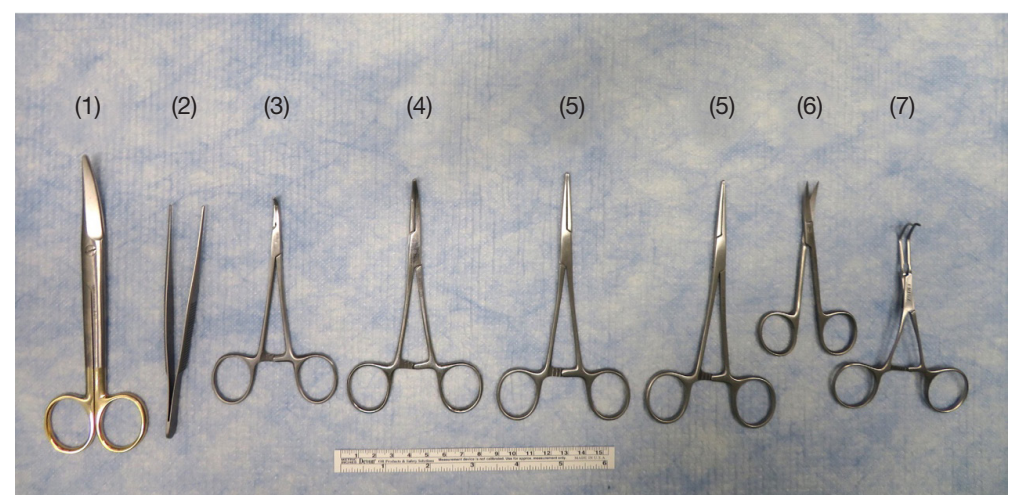

Figure S1 These instruments are used for donor graft retrieval. (1) Mayo scissors curved with carbide tips L140 mm, Natsume Seisakusho Co., Ltd, Tokyo, Japan. (2) Tweezers with fine tip without hook straight type L130 mm, Natsume Seisakusho Co., Ltd, Tokyo, Japan. (3) Micro-Mosquito Angled 90, Fine Science Tools, , Inc British Columbia, Canada. (4) Kelly hemostatic forceps $14 \mathrm{~cm}$ curved, Bioresearch Center Co., Ltd., Aichi, Japan. (5) Kelly hemostatic forceps $14 \mathrm{~cm}$ straight, Bioresearch Center Co., Ltd., Aichi, Japan. (6) Extra Fine Bonn Curved sharp/sharp 8.5 cm, Fine Science Tools, Inc., British Columbia, Canada. (7) Blood Vessel Clamp Satinsky 12 cm, Dr.Frigz International(Pvt)Ltd, Sialkot, Pakistan.

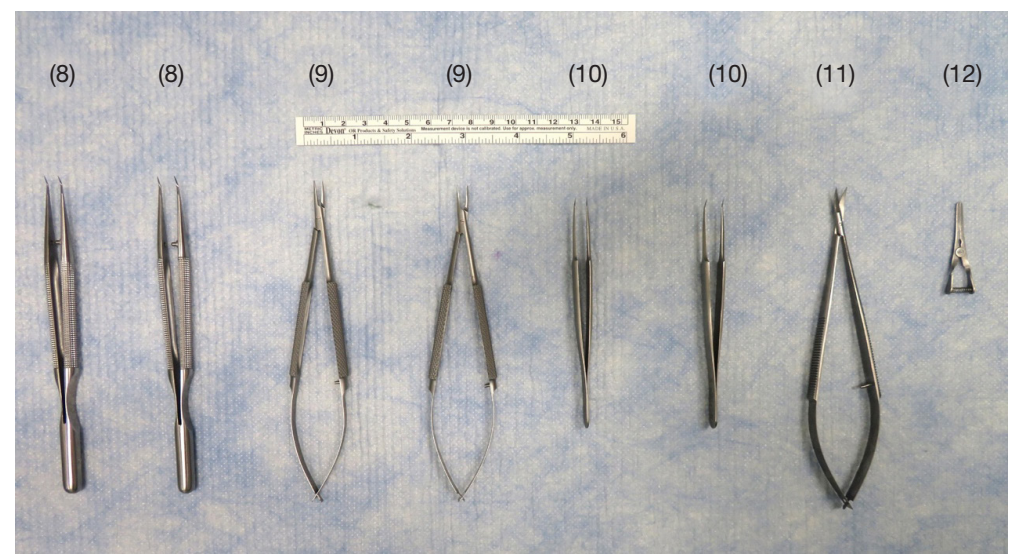

Figure S2 These instruments are used for graft cuff preparation. (8) Vessel Dilator (Angled), Fine Science Tools, British Columbia, Canada. (9) Micro Needle holder curved L155 mm, Natsume Seisakusho Co., Ltd, Tokyo, Japan. (10) Dumont \#5/45, Fine Science Tools, Inc., British Columbia, Canada. (11) Microspring scissors $15 \mathrm{~cm}$ curved, Bioresearch Center Co., Ltd., Aichi, Japan. (12) Bulldog clamp straight W $0.9 \mathrm{~mm} \times$ L $17 \mathrm{~mm}$, Natsume Seisakusho Co., Ltd, Tokyo, Japan. 


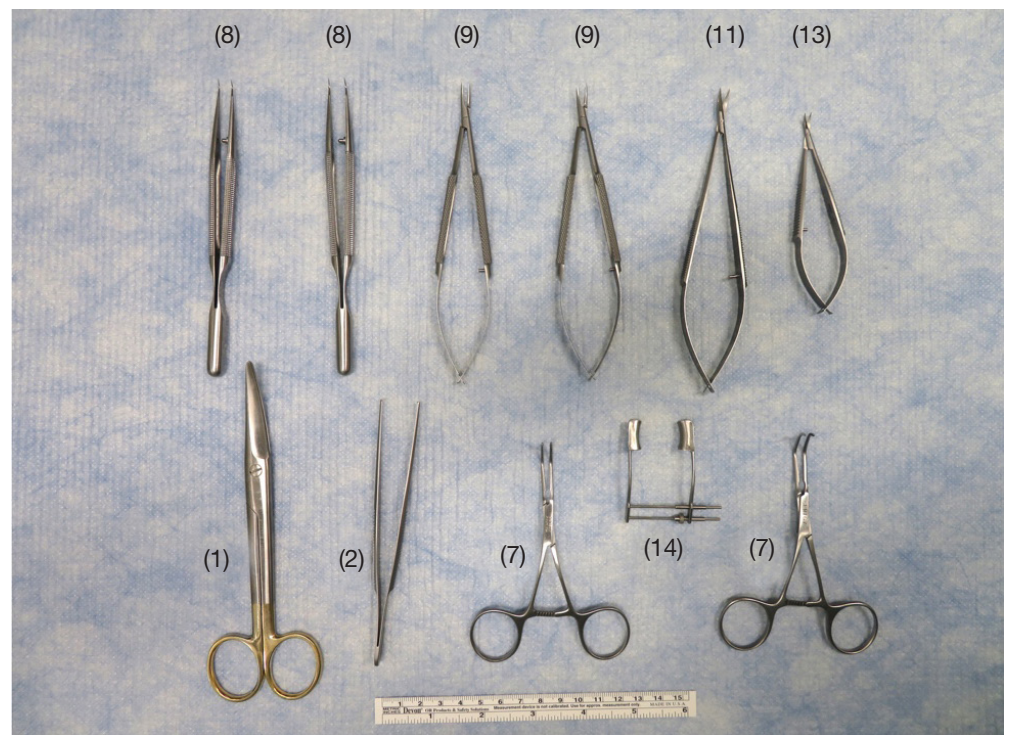

Figure S3 These instruments are used for implantation/anastomosis. (1) Mayo scissors curved with carbide tips L140 mm, Natsume Seisakusho Co., Ltd, Tokyo, Japan. (2) Tweezers with fine tip without hook straight type L130 mm, Natsume Seisakusho Co., Ltd, Tokyo, Japan. (7) Blood Vessel Clamp Satinsky 12 cm, Dr.Frigz International(Pvt)Ltd, Sialkot, Pakistan. (8) Vessel Dilator (Angled), Fine Science Tools, Inc., British Columbia, Canada. (9) Micro Needle holder curved L155 mm, Natsume Seisakusho Co., Ltd, Tokyo, Japan. (11) Microspring scissors $15 \mathrm{~cm}$ curved, Bioresearch Center Co., Ltd., Aichi, Japan. (13) Micro scissors curved L105 mm Cutting Edge 7 mm, Natsume Seisakusho Co., Ltd, Tokyo, Japan. (14) Speculum BANGERTER Large Right, Inami \& Co., Ltd., Tokyo, Japan.

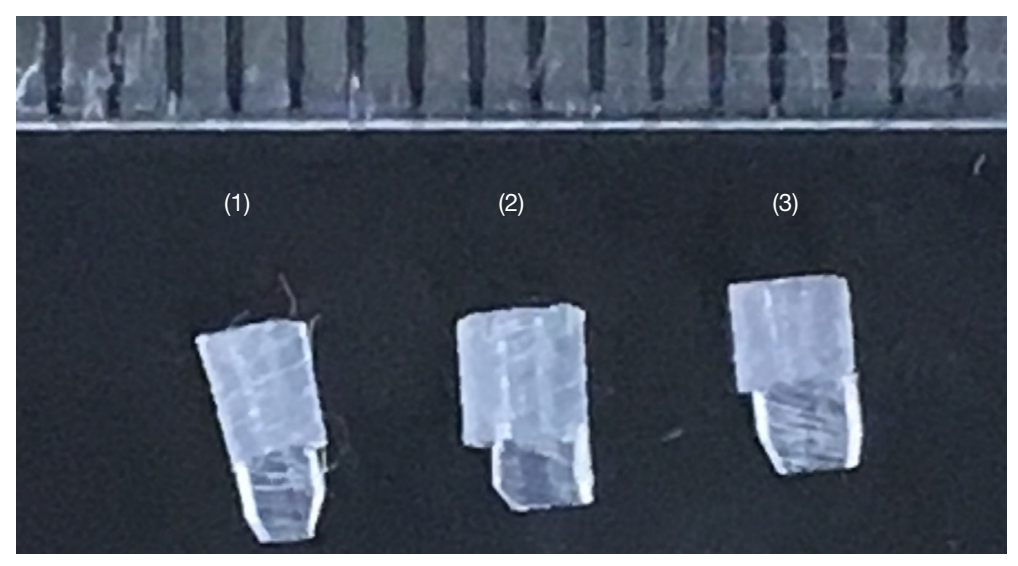

Figure S4 Cuffs with round tail. 


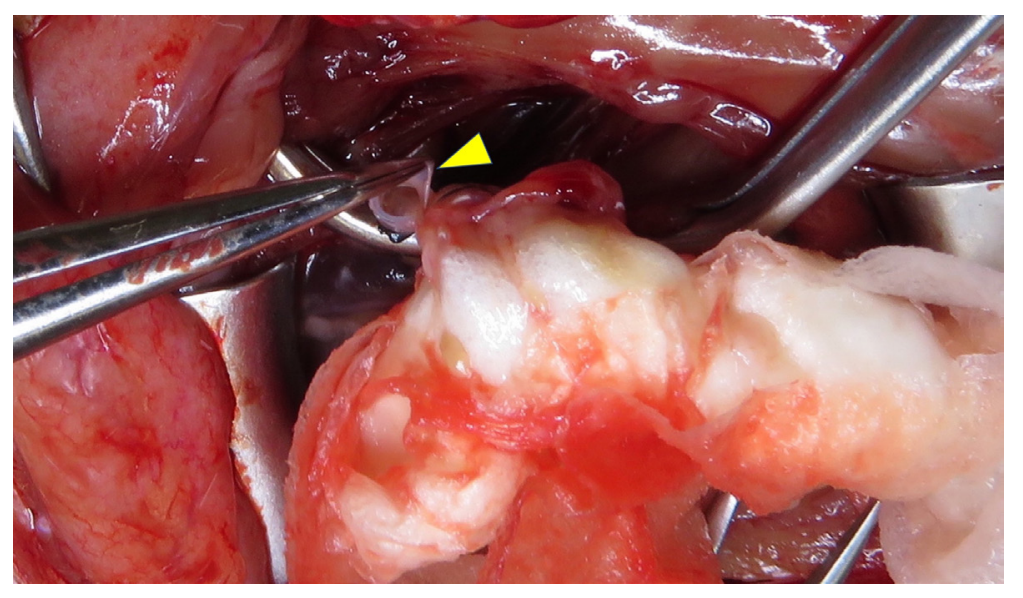

Figure S5 Cut the end rim of native structures (arrow). 